\title{
Compensación humana de déficits de la traducción automática ${ }^{1}$
}

\section{(Human Compensation of Machine Translation Gaps)}

\author{
Anna Aguilar-Amat ${ }^{2}$
}

Universitat Autònoma de Barcelona, Barcelona, España

\section{Olga Torres-Hostench ${ }^{3}$}

Universitat Autònoma de Barcelona, Barcelona, España

\begin{abstract}
RESUMEN
En el contexto del tránsito de la sociedad de la información al ciberhumanismo, se explora la relación persona-máquina desde una perspectiva psico-traductológica centrada en el usuario. Comprender la causa de los errores de la traducción automática (TA) ampliando la conciencia lingüístico-cognitiva permite optimizar la recepción del mensaje. A partir de ejemplos reales de uso de la TA se distinguen tres tipos de usuarios y formulamos un nuevo matiz del concepto de 'compensación' (empatía cognitiva) que completa el esquema de la comunicación de Jakobson. Las respuestas empático-cognitivas a los errores de la TA, activas y proactivas, son un factor clave de la comunicación multilingüe.
\end{abstract}

1 Recibido: 14 de abril de 2020; aceptado: 5 de abril de 2021. Este trabajo se ha realizado en el marco del proyecto: «DESCRIPCIÓN DEL POST-EDITESE EN TRADUCCIÓN AUTOMÁTICA (DESPITE-MT)», proyecto del Ministerio de Ciencia, Innovación y Universidades. Programa Estatal de Investigación, Desarrollo e Innovación Orientada a los Retos de la Sociedad. (ref. PID2019-108650RB-I00). Grup Tradumàtica, Universidad Autónoma de Barcelona. [Esta nota fue actualizada el 23 de junio de 2021].

2 Terminología. Grupo Tradumática. Departamento de Traducción, Interpretación y Estudios de Asia Oriental; https://orcid.org/0000-0001-7257-6293. Correo electrónico: anna.aguilar-amat@uab.cat

3 Traducción. Grupo Tradumática. Departamento de Traducción, Interpretación y Estudios de Asia Oriental; https://orcid.org/0000-0003-1525-0304.Correo electrónico: olga.torres.hostench@uab.cat

LETRAS 70 (2021), ISSN 1409-424X; EISSN 2215-4094

DOI: http://dx.doi.org/10.15359/rl.2-70.5

www.revistas.una.ac.cr/index.php/letras 


\begin{abstract}
In the context of the transition from the information society to cyberhumanism, the human-machine relationship is explored from a usercentered psycho-translational perspective. Understanding the reasons for machine translation (MT) errors by expanding linguistic-cognitive awareness allows us to optimize message reception. Based on real examples of MT use, three types of users are distinguished and a novel nuance is formulated of the concept of 'compensation' (cognitive empathy) that completes Jakobson's communication scheme. Active and proactive cognitive-empathetic responses to MT errors are a key factor in multilingual communication.
\end{abstract}

Palabras clave: relación persona-máquina, empatía cognitiva, traducción automática, lingüística de corpus, terminología

Keywords: human-machine environment, cognitive empathy, machine translation, corpus linguistics, terminology

\title{
Introducción: la plasticidad cerebral
}

Con la llegada de los sistemas de TA gratuitos orientados a sectores no profesionales de la traducción (Google Translate, DeepL, Apertium, iTranslate4, Microsoft Translator, PROMT.one, Lucy LT, entre otros), el uso de TA se ha generalizado y es utilizada por millones de personas cada día. Las administraciones públicas también ofrecen servicios de traducción automática con portales como eTranslatio ${ }^{4}$. La TA gratuita puede llegar a superar el volumen de traducciones realizado por profesionales y se consolida como sistema de comunicación de urgencia entre agentes que no dominan la lengua de su interlocutor.

En el presente estudio reflexionamos sobre el uso de traducción automática (TA) desde una perspectiva centrada en el usuario o receptor de la TA online, más allá del circuito de la traducción profesional. El receptor no se concibe como sujeto pasivo sino como sujeto activo, con plasticidad cerebral suficiente para realizar

4 Comisión Europea, «eTranslation», fecha de consulta: septiembre de 2020, <https://ec.europa.eu/ info/resources-partners/machine-translation-public-administrations-etranslation_en>. 
una compensación de los déficits de la traducción automática y repararla en el caso de mensajes incorrectos, para lo cual precisa también de la actitud psicológica adecuada (ver apartado Aspectos cognitivos del usuario de la TA).

No se parte de una muestra prediseñada ante un problema acotado, con unas hipótesis y metodología que dan pie a resultados numéricos; extrapolar la estadística de una muestra al enorme conjunto de usuarios de la TA sería una reducción que falsearía la verdad. Lo que las autoras hacen en este artículo ensayístico es describir distintas situaciones en que la TA forma parte de la comunicación y plantear un ángulo distinto para la observación de la TA que se centra en las características del usuario humano. De esta forma se sientan algunas bases para la investigación futura en este campo.

Empezaremos hablando de la plasticidad cerebral, entendida como el aprendizaje, la adquisición de habilidades, las influencias interpersonales y sociales y otras variables del contexto que pueden ejercer un efecto en la estructura física del cerebro, modificándolo y estableciendo nuevas relaciones y circuitos neurales que a su vez alteran su funcionamiento ${ }^{5}$. El concepto ha sido divulgado como la capacidad de ver el lado positivo de los cambios para desarrollar comportamientos diferentes ${ }^{6}$ : «ante un contratiempo la mente busca un equilibrio de forma natural». Los patrones rígidos conducen al desconcierto de la persona que posteriormente consigue un reequilibrio buscando siempre la visión de conjunto. Esto sucede como respuesta emocional en las distintas situaciones vitales, y también se aplica a la descodificación de un texto que, traducido de manera automática, presenta ciertos déficits de lenguaje. Distinguimos diversos grupos de usuarios y describimos su recepción de la TA, y a partir de aquí anticipamos una ampliación de la capacidad lingüístico-cognitiva

5 Carlos-María Alcover y Fernando Rodríguez Mazo, «Plasticidad cerebral y hábito en William James: un antecedente para la neurociencia social», Psychologia Latina 3, 1 (2012): 1-9. DOI: http:// dx.doi.org/10.5209/rev_PSLA.2012.v3.n1.38737.

6 Elsa Punset, Brújula para navegantes emocionales (Barcelona: Aguilar, 2018): 130. 
fruto de la comprensión o empatía cognitiva hacia el porqué de los errores cometidos por el programa informático para conseguir la compensación útil del mensaje. El nuevo mensajero o canal que es la máquina nos dice cosas sobre el funcionamiento del lenguaje, y en vez de «matar al mensajero» podemos evolucionar y ampliar nuestra conciencia lingüística.

Desarrollamos la siguiente estructura argumental: a partir de resultados de una encuesta sobre los propósitos del usuario en el uso de la TA, se distinguen tres tipos de usuarios: 1) usuarios sensibles al idioma (language-sensitive users), 2) usuarios no sensibles al idioma (non-language-sensitive users), 3) usuarios de la TA en proceso de adquisición del idioma. Seguidamente se describen algunos de los principales problemas que plantea la TA en función del uso que hace cada grupo de usuarios, i.e. se focaliza la TA de terminología y de variación denominativa, así como la TA de colocaciones neológicas para los dos primeros grupos, y se comunican los resultados de un estudio realizado con estudiantes de bachillerato en el caso del tercer grupo. Unificando de nuevo a los usuarios de la TA, y tras analizar distintos procedimientos y ejemplos de compensación del texto resultante de la TA, se resumen los aspectos psicológicos y lingüísticos para una compensación óptima de la TA. Se propone una nueva función, la función empática, que complementa el modelo funcional de la comunicación propuesto en los años sesenta.

\section{Popularización de la traducción automática (TA)}

Las ventajas más visibles de la TA para los usuarios son la rapidez, el ahorro de costes y el procesamiento de volúmenes mayores de texto. Pero probablemente lo más importante es que permite superar barreras lingüísticas. En el informe TAUS Translation Data Landscape Report $^{7}$ sobre la era de la convergencia tecnológica y la digitalización

7 Andrew Joscelyne, Anna Samiotou y Japp Van der Meer, TAUS Translation Data Landscape Report (2015) Fecha de consulta: febrero $2020<$ https://www.taus.net/think-tank/reports/ translate-reports/taus-translation-data-landscape-report>. 
se afirma que las tecnologías para la traducción convergen en dispositivos digitales y que la interfaz de cada dispositivo tendrá el potencial de gestionar información multilingüe. Esta capacidad de superar las barreras lingüísticas está ya al alcance de todo tipo de usuarios, pero no sabemos cuál es su aprovechamiento real. De hecho, un reciente estudio sobre el uso de la TA en las empresas de servicios lingüísticos del ámbito español ${ }^{8}$ muestra la escasez de respuestas positivas sobre el uso de esta herramienta en los procesos de traducción profesional.

Sin embargo, la TA es una herramienta imprescindible para la comunicación de lenguas distintas del inglés con el inglés y entre ellas, para acceder a lo aún no traducido, y es a la vez una posibilidad de supervivencia para las lenguas con menor número de hablantes o de recursos. En el ámbito de la naturaleza de las lenguas icónicas, en concreto del pidgin, Masterman ${ }^{9}$ señaló: «In practice it might become expedient to deviate from our preconceptions considerably in whatever way aids the reader» (en la práctica, podría ser conveniente desviarse considerablemente de nuestras ideas preconcebidas de cualquier manera que ayude al lector), animando a los estudiosos a cambiar el punto de vista sobre este tipo de estudios.

Para diversos autores la TA tiene dos usos fundamentales: 1) la asimilación, es decir, se utiliza para permitir al usuario entender el contenido del texto; o 2) para la diseminación, es decir, se utiliza para ayudar en la traducción de un texto que va a ser publicado (siendo sometido, con frecuencia, a un proceso de preedición ${ }^{10} \mathrm{y}$, necesariamente, a un proceso de postedición en la que interviene

8 Olga Torres-Hostench y otros, «El uso de traducción automática y posedición en las empresas de servicios lingüísticos españolas: Informe de investigación», ProjecTA 2015 (Bellaterra: Universitat Autònoma de Barcelona: 2016), <https://ddd.uab.cat/record/148361>.

9 Margaret Masterman, «Mechanical Pidgin Translation», Language, Cohesion and Form (2005), fecha de consulta: marzo de 2020, <https://www.cambridge.org/core/books/ language-cohesion-and-form/mechanical-pidgin-translation/>.

CC54CD6CF8F86C9DF1F244E19F48D617>DOI: https://doi.org/10.1017/CBO9780511486609.009, p. 161-186.

10 La preedición solo es rentable cuando se traducen automáticamente documentos a más de una lengua o cuando los textos preeditados se van a utilizar en el futuro, ya que el coste de cada operación (proactiva) de preedición es más caro que el de cada operación (defensiva) de postedición. 
un humano $)^{11}$. Pero ¿qué dicen los usuarios de la TA? En un sondeo realizado a usuarios de redes sociales en el marco de un seminario de traducción automática (2020), sobre 268 personas se muestra que entre dichos usuarios el uso de la TA para fines personales es superior a otros posibles usos como se indica en el cuadro 1. Como se indica en el cuadro, el mayor uso detectado de la traducción automática es como diccionario, seguido de traducción de un idioma extranjero, y en tercer lugar para fines personales.

Cuadro 1. Usos de la TA

\begin{tabular}{|l|c|c|}
\hline \multicolumn{3}{|c|}{ ¿Con qué propósito usa la TA? } \\
\hline \multicolumn{1}{|c|}{ Fines } & Cantidad & Porcentaje \\
\hline Para fines personales & 101 & $37,7 \%$ \\
\hline Para fines profesionales & 79 & $29,5 \%$ \\
\hline Como diccionario & 85 & $31,7 \%$ \\
\hline Para escribir en otro idioma & 139 & $51,9 \%$ \\
\hline Para traducir a idioma propio & 110 & $41 \%$ \\
\hline Rectificar y mejorar textos & 1 & $0,4 \%$ \\
\hline No la uso & 5 & $2 \%$ \\
\hline Ninguna de las anteriores & 1 & $0,4 \%$ \\
\hline
\end{tabular}

Fuente: Elaboración propia a partir de encuesta a 268 participantes ${ }^{12}$

¿En qué situaciones se ha extendido la TA? En aquellas situaciones en las que los usuarios necesitan conocer la información del mensaje de manera inmediata y/o sucinta y no encargan una traducción profesional. A menudo este uso se produce en situaciones en las que usuarios digitales tienen una necesidad específica. En el ámbito de la empresa, hablamos de profesionales que necesitan entender rápidamente información de la competencia, de clientes o de proveedores (mensajes electrónicos, sitios web, informes publicados, instrucciones

11 Kenneth Jordan Núñez, «Análisis de la percepción, la utilidad y la calidad de los sistemas de TA por parte del traductor en formación», E-Aesla 5 (2019): $392<\mathrm{https://cvc.cervantes.es/lengua/}$ eaesla/pdf/05/38.pdf $>$.

12 Olga Torres-Hostench, «Materiales didácticos propios de un seminario sobre traducción automática», 2020 (literatura gris). 
de funcionamiento de aparatos, noticias especializadas, etc.). En las relaciones con la administración pública, ciudadanos extranjeros necesitan entender documentación administrativa. En el sector educativo profesores y estudiantes de todas las disciplinas necesitan acceder a información especializada no traducida relacionada con las asignaturas o sus líneas de investigación. En el sector de la salud, tanto profesionales sanitarios como pacientes utilizan traducción automática para poder acceder a información especializada no traducida sobre síntomas y tratamientos. En el sector del turismo, ocio y servicios, muchos consumidores utilizan TA online para informarse antes de tomar una decisión de compra ${ }^{13}$. Son muchos los ciudadanos de la sociedad digital que necesitan la TA antes de tomar decisiones que para ellos son importantes. En este contexto, el ciudadano puede obtener satisfacción de la TA si concibe el texto resultante como un estadio diferente de la lengua que requiere una reparación y cierto aprendizaje por su parte para utilizarlo. Por otro lado, muchos de los textos que consultamos en la red pueden ser resultado de procesos de traducción automática. Pero ¿de qué manera afecta la TA a la comprensión de los contenidos y cómo moldea un mecanismo tan antiguo como la lectura?

El hablante, que se expresa con naturalidad y espera de un automatismo que consiga hacer lo mismo, a menudo se siente defraudado con el resultado de la TA, pero lo cierto es que con una mayor conciencia lingüística es posible predecir, compensar, entender y reparar los errores cometidos por la máquina, ya que muchos de ellos son fruto de ambigüedades ya existentes en el discurso que compensamos con el conocimiento del mundo que poseemos como humanos.

La tolerancia de los usuarios de la era digital aumenta de manera progresiva (hace unos años, utilizar idiotismos — giros anómalos—en la redacción de mensajes enviados a través del móvil estaba mal visto, por ejemplo, pero ahora se acepta como mal menor para optimizar el tiempo: los padres se han acostumbrado a leer los mensajes que

13 Miguel Ángel Candel-Mora y Carla Borja-Tormo, «Desarrollo de la aplicación Post-editing Calculeffort para la estimación del esfuerzo en posedición», Tradumàtica 15 (2017): 1-9. 
envían los hijos por móvil con sus nuevos códigos («tqm» por «te quiero mucho», «lol» por laughing out loud), los cuales no sustituyen al lenguaje natural sino que lo complementan, de manera que una competencia no excluye a otra ${ }^{14}$.

Así, entendemos que el usuario es capaz de usar distintos registros sin perder habilidad comunicativa pero no está exento de efectuar ciertas modificaciones en su sistema cognitivo aprehendido por lo que concierne a la descodificación de los mensajes.

\section{Tipos de usuarios de la traducción automática}

Existe un abanico amplio de usuarios de la traducción automática, puesto que ésta está presente en las redes sociales y en muchas páginas web, de manera que no siempre los usuarios somos conscientes de estar leyendo textos traducidos automáticamente. El abanico va desde el traductor profesional con conocimientos sobre el funcionamiento de los motores de TA, al lego sin conocimiento lingüístico, ni informático, ni del idioma original (origen o meta). Entre estos dos polos está el lego con conocimiento del idioma original y el mediador con conciencia lingüística pero que desconoce la lengua origen del caso particular, entre otros.

A sabiendas de que los usuarios de la traducción automática son muy diversos y que las variables como hablante son enormes (se podría decir que cada usuario tiene particularidades únicas que se constituyen precisamente a partir del lenguaje y del uso que haga de él), en este artículo reflexionamos sobre la experiencia con TA en tres tipos de usuarios: 1) usuarios sensibles al idioma (language-sensitive users); 2) usuarios no sensibles al idioma (non-language-sensitive users); y 3) usuarios de la TA en proceso de adquisición del idioma.

En el grupo 1 se incluyen los traductores y los mediadores lingüísticos en general, así como los estudiosos del idioma, filólogos y

14 Crispin Thurlow y Alex Brown, «Generation Txt? The Sociolinguistics of Young People's TextMessaging» Discourse Analysis Online 1, 1 (2003): 30. 
lingüistas, pero también profesionales que manifiestan cierto prurito por el hecho de comunicarse correctamente en lenguas extranjeras en sus actividades profesionales (de una traducción correcta puede depender una ganancia o pérdida económica, etc.).

En el grupo 2 se incluyen los clientes, es decir, las personas que utilizan la traducción automática para acceder a un determinado contenido (turístico, médico, transaccional) y que, debido a los errores o incorreciones que dificultan la comunicación, van a omitir el mensaje y darse por vencidos en cuanto a sus objetivos prácticos (la decisión a tomar sobre, por ejemplo, una reserva hotelera, y el posible desistimiento en la búsqueda de más información).

En el grupo 3 se incluye a los usuarios de la TA en proceso de adquisición de la competencia del idioma. En el marco del proyecto ProjecTA-U, financiado por el Ministerio español de Economía y Competitividad y coordinado desde la Universitat Autònoma de Barcelona (FFI2016-78612-R), se realizó un sondeo a estudiantes de secundaria y a estudiantes universitarios de español como segunda lengua. Estos colectivos en proceso de formación podrían incluirse en el grupo 1 y también en el grupo 2 de usuarios no sensibles al idioma con motivación fáctica, porque la motivación fáctica de este grupo de estudiantes en formación es el idioma en sí mismo. Para facilitar la argumentación los hemos considerado en grupo aparte.

\section{Usuarios de la TA sensibles al idioma (language-sensitive users)}

Actualmente, gracias al perfeccionamiento de los sistemas de traducción automática, son muchas las empresas de traducción que deciden o se están planteando utilizar la traducción automática como fuente de una primera traducción (según el informe de SDL, 2010, más de un $25 \%$ de las grandes empresas de localización se encontrarían en esta situación). Estas traducciones, conocidas como traducciones en bruto, pasan posteriormente por un proceso de posedición, es decir, 
un proceso de «revisar y corregir traducciones producidas por algún método de traducción automática» ${ }^{15}$.

La industria cuenta con algunas propuestas en forma de guías de estilo o directrices que orientan a los traductores encargados del proceso de posedición, como, por ejemplo, las directrices GALE (NIST, 2007), o el informe de TAUS «Postediting in Practice» (TAUS, 2010). En el proyecto POST-IT sobre formación de poseditores (ref. FFI2011-16021-E) se proponía abordar este problema elaborando un modelo de control de la calidad de las traducciones para guiar a los poseditores y que fuera compartido por todos los agentes involucrados en la industria de la traducción. El proyecto Calculeffort ${ }^{16}$ permite calcular el esfuerzo necesario en términos económicos y humanos y calcular el coste de la posedición en función de los déficits que pueda presentar la traducción automática obtenida.

Así, en el sector profesional, al ya habitual uso de las herramientas TAO (traducción asistida por ordenador) que reducen considerablemente el tiempo empleado en traducir textos con repeticiones y de características similares, se suma la actividad de posedición de textos traducidos automáticamente tal y como se constata en el informe elaborado a partir del proyecto financiado ProjecTA (ref. FFI201346041-R) sobre el uso de la traducción automática en las empresas de servicios lingüísticos españolas ${ }^{17}$. En él se pone de manifiesto que ya no resulta cierta la afirmación de que es menos costoso traducir manualmente que corregir los errores de la traducción automática.

La introducción de la TA en el flujo de trabajo es un tema que interesa y abordan tanto empresas tales como SDL a través de su informe «Trends in Automated Translation in Today’s Global Business ${ }^{18}$,

15 Daniel Gouadec, Translation as a Profession, Vol. 73 (Amsterdam: John Benjamins Publishing, 2007) 25.

16 Candel-Mora y Borja-Tormo, 1-9.

17 Torres-Hostench y otros, 20.

18 Sophie Hurst, «Trends in Automated Translation in Today's Global Business», The Eighth Conference of the Association for Machine translation in the Americas, 2008. http://mt-archive.info/ AMTA-2008-Hurst.pdf. 
así como asociaciones y organismos internacionales tales como los informes sobre TA y posedición de la Translation Automaton User Society ${ }^{19}$, o la Best Practices Guide sobre TA de LISA ${ }^{20}$, que incluye un apartado exclusivo sobre posedición.

Junto con la posedición, el usuario sensible al idioma entiende que debe a menudo preeditar el texto para obtener los resultados esperados. En el caso de la terminología, por ejemplo, será preciso compensar las colocaciones que han sufrido elisiones $y$, por poner un ejemplo, buscar y substituir 'perturbación' por 'perturbación atmosférica' para evitar resultados que no se corresponden con el dominio y evitar errores de precisión:

(es) perturbación atmosférica / (en) atmospheric disturbance (ecología)

(es) perturbación social / (en) social disruption (sociología)

(es) perturbación del mercado / (en) market turmoil (economía)

El usuario sensible al idioma suele utilizar otras herramientas como diccionarios en línea (WordReference.com) o bases de datos de traducciones (Linguee.es) que le permiten reducir las ambigüedades hasta el máximo deseable, o herramientas avanzadas de interrogación (interpelación) de corpus como AntConc o Sketch Engine. Aun así, los errores de terminología pueden escapar al conocimiento del mediador lingüístico no experto en el dominio específico, y es por ese motivo que incluimos en este grupo de usuarios a los expertos y los técnicos, los cuales tienen capacidad para detectar errores conceptuales de la TA. (Entendemos por otro lado que cualquier usuario tiene algún grado de experiencia y pericia (expertise) en las áreas de su cotidianeidad).

En el siguiente ejemplo el término blue fish se traduce automáticamente como «pescado azul» cuando en realidad se trataría de una «anchoa de banco» (Pomatomus saltatrix) como se ve en el cuadro 2.

19 Andrew Joscelyne y Colin Brace, Postediting in Practice. A TAUS Report, $2010<\mathrm{https}$ ://www. taus.net/think-tank/reports/postedit-reports/postediting-in-practice>.

20 Mike Dillinger and Arle Lommel, LISA Best Practice Guide. Implementing Machine translation (Switzerland: Localization Industry Standards Association, 2004). 
Cuadro 2. Ejemplos de errores terminológicos de la TA

\begin{tabular}{|l|l|l|l|}
\hline $\begin{array}{c}\text { Término en } \\
\text { inglés }\end{array}$ & $\begin{array}{c}\text { Traducción } \\
\text { automática (Google } \\
\text { Translator, 2019) }\end{array}$ & $\begin{array}{c}\text { Traducción } \\
\text { correcta } \\
\text { en español } \\
\text { peninsular }\end{array}$ & \multicolumn{1}{|c|}{$\begin{array}{c}\text { Distorsión de } \\
\text { significado de la TA }\end{array}$} \\
\hline blue fish & *pescado azul & $\begin{array}{l}\text { anchova -o } \\
\text { anchoa- de } \\
\text { banco }\end{array}$ & $\begin{array}{l}\text { se confunde con 'pescado } \\
\text { rico en omega 3' }\end{array}$ \\
\hline fat fish & *pez gordo & pescado azul & $\begin{array}{l}\text { no se obtiene la } \\
\text { información correcta }\end{array}$ \\
\hline lean fish & *pescado magro & pescado blanco & $\begin{array}{l}\text { comprensible pero no } \\
\text { usado, la información } \\
\text { disminuye }\end{array}$ \\
\hline
\end{tabular}

Fuente: elaboración propia.

El proceso de posedición implica un grado de documentación suplementaria por parte del usuario sensible al idioma y que escapa al mero conocimiento lingüístico. El traductor humano $(\mathrm{TH})$ es plenamente consciente de que muchos textos, aunque no sean estrictamente literarios, precisan de cierta recreación estilística, por lo que el resultado de la traducción automática va a ser distante de los recursos expresivos necesarios, los cuales deberá proveer más tarde. Este tipo de posedición corrige desviaciones de fluidez discursiva. En este ejemplo extraído de Viaje de un naturalista alrededor del mundo a bordo del Beagle, por Charles Darwin ${ }^{21}$, vemos como la TA ha mejorado sustancialmente su resultado desde 2016 a 2019, pero aun así el traductor humano recrea el texto de modo particular, e incluso en el caso de ese fragmento, introduce ciertos cambios interpretativos, que podrían ser discutibles:

21 Charles Darwin, Journal of Researches into the Geology and Natural History of the Various Countries Visited by H.M.S. Beagle. (London: Henry Colburn. $3^{\mathrm{a}}$ ed., 1839); traducido por Manuel Vílchez de Serradell, Viaje de un naturalista alrededor del mundo (NoBooks Editorial, 2015), 301. 
Original (Charles Darwin, 1839)

It rains very seldom, but during a short portion of the year heavy torrents fall, and immediately afterwards a light vegetation springs out of every crevice. This soon withers; and upon such naturally formed hay the animals live. It had not now rained for an entire year.

TA (Google Translator, 2016)

Llueve muy rara vez, pero durante un corto $\square$ parte del año torrentes pesados caída, e inmediatamente después una vegetación luz $\square$ brota de cada grieta. Esto pronto se marchita; y sobre tal manera natural $\square$ heno formado los animales viven. No se había llovido durante todo un año.

\section{TA (Google Translator, 2019)}

Rara vez llueve, pero durante una breve porción del año caen torrentes pesados e inmediatamente después brota una vegetación ligera de cada grieta. Esto pronto se marchita; y sobre tal heno formado naturalmente viven los animales. No había llovido durante un año entero.

\section{Traductor humano (Vilchez de Serradell, 1906)22}

Rara vez llueve, excepto una pequeña parte del año; entonces cae a torrentes la lluvia, y enseguida invade cada grieta abundante vegetación. Esas plantas se agostan casi tan deprisa como brotaron, y los animales se alimentan de ese heno natural. Cuando estuvimos nosotros, llevaba más de uno año sin llover.

El traductor humano $(\mathrm{TH})$ traduce light vegetation como «abundante vegetación» mientras que el traductor automático opta por «vegetación ligera», (pensamos que lo propio sería «suave vegetación»), por lo que queda claro que las inexactitudes o ambigüedades son connaturales al proceso de traducción tanto humana como automática.

22 Manuel Vílchez de Serradell, Viaje de un naturalista alrededor del mundo, original de 1906, publicado por NoBooks Editorial 2015, Colección narrativa $\mathrm{n}^{\circ}$ 635. Traducción del libro de Charles Darwin, Journal of Researches into the Geology and Natural History of the Various Countries Visited by H.M.S. Beagle. $3^{\text {a }}$ ed. London: Henry Colburn (1939, 1a ed. 1840). 
Los ejemplos anteriores redundan en el hecho de que en vez de traducir un texto de la nada, es posible optar por rectificar y pulir un borrador para que alcance un nivel de calidad y comprensión aceptables. La posedición es un paso ineludible para el usuario sensible al idioma y es previsible un aumento progresivo de la TA para determinados pares de lenguas. Así las cosas, la ambivalencia para el profesional no es entre TH y TA sino entre TH y posedición de TA.

La evaluación inicial de la TA es también una fase importante en las tareas de posedición profesional puesto que sirve para determinar si se aprovecha la TA (y en consecuencia se postedita) o bien se descarta la TA (y la frase se traduce de cero). Algunas empresas tecnológicas aplican la regla del 2-second-rule que consiste en pedir al poseditor que evalúe durante dos segundos si la frase de TA se puede aprovechar o no.

La bibliografía existente ${ }^{23}$ muestra el interés en calcular el esfuerzo de posedición mediante el registro del tiempo de posedición (registros temporales), registros de rastreo de la mirada y análisis de grabaciones de registros de procesos mentales y registros del esfuerzo técnico con el uso del teclado. Cabe señalar que existe, en la bibliografía sobre este tema, un debate sobre si la posedición es una labor que solo deben llevar a cabo traductores profesionales. Según Krings y Koby ${ }^{24}$, solo un traductor puede juzgar la precisión de una traducción, pues es el más capacitado para detectar errores en

23 Hans P. Krings y Geoffrey S. Koby, Repairing Texts: Empirical Investigations of Machine Translation Post-editing Processes, (Kent: Kent State University Press, 2001); Sharon O’Brien, «Methodologies for measuring the correlations between post-editing effort and machine translatability», Machine Translation 19,1 (2005): 37-58. DOI: 10.1007/s10590-005-2467-1; Irina P. Temnikova, «Cognitive Evaluation Approach for a Controlled Language Post-Editing Experiment» LREC, $2010<\mathrm{https}$ //www.aclweb.org/anthology/L10-1300/>; Isabel Lacruz, Michael Denkowski y Alon Lavie, «Cognitive Demand and Cognitive Effort in Post-Editing» (AMTA, 2014); Lucas Nunes Vieira, «Indices of cognitive effort in machine translation post-editing» Machine Translation, 28, 3-4, (2014): 187-216. DOI: 10.1007/s10590-014-9156-x; Thierry Etchegoyhen y otros, «Quales: Estimación automática de calidad de traducción mediante aprendizaje automático supervisado y no-supervisado», Procesamiento del lenguaje natural 61 (2018): 143-146 http://rua. ua.es/dspace/handle/10045/81358. DOI: 10.26342/2018-61-18.

24 Vílchez de Serradell. 
la traducción automática, cuenta con conocimientos de interferencia lingüística entre dos idiomas y con recursos tecnológicos que sabe utilizar en caso de duda.

Pero si la posedición solo define lo que hacen los profesionales, ¿cómo debemos llamar al proceso según el cual un usuario no sensible al idioma «enmienda» el texto resultante de la TA para conseguir una comunicación satisfactoria? ¿Y cuál es el proceso cognitivo que le hace capaz o incapaz de reconocer los errores? La «enmienda» del texto por un receptor no sensible al idioma lo llamamos reparación cognitiva, lingüística o fáctica, y no es propiamente una traducción puesto que el receptor, al dirigir su atención, es posible que omite cosas. (Si el usuario es no sensible al idioma, es improbable que se publique su texto, puesto que sólo se va a publicaría el resultado de un trabajo profesional).

\section{Usuarios de la TA no sensibles al idioma (non-language-sensitive users)}

Los usuarios considerados en este grupo son los que utilizan la TA con una finalidad específica y fáctica: el uso de un medicamento, el funcionamiento de una máquina, la reserva de un hotel, la visita a un destino turístico, la elaboración de una receta culinaria, etc. Este tipo de usuario no se preocupa por la bondad del mensaje y omite todo aquello que le aleja del objetivo perseguido: una vez averigua que el hotel tiene piscina y wifi, por poner un ejemplo, deja de preocuparse por el resto de información (o desinformación). Curiosamente, este tipo de usuarios realiza de modo inconsciente profundos procesos de reparación (lo que denominaremos 'empatía cognitivo-comunicativa') para descodificar el mensaje distorsionado por la TA, puesto que su motivación es muy alta.

Veamos un ejemplo de este proceso. La siguiente frase es el resultado de una traducción automática del inglés al castellano de las instrucciones de un dispositivo: «Sea cuidadosamente guardarlo sin caerlo». El mensaje está expresado de un modo muy deficiente, pero aún puede resultar comprensible para el usuario motivado en entender 
las instrucciones de dicho dispositivo. El proceso por el que pasa el usuario es el de identificar nodos semánticos (ser cuidadoso, guardar, no dejar que caiga al suelo) y después reconstruye la frase para sí mismo: «Tengo que guardar el objeto con cuidado para que no se caiga» o «éste es un objeto frágil». Puesto que la TA lleva al usuario a proceder correctamente tras la comprensión de las instrucciones, el usuario quedará satisfecho y considerará que el programa de TA le ha aportado una ayuda valiosa. Además, se sentirá complacido de su proceso cognitivo de reparación y de su superioridad ante la máquina, lo cual le llevará a seguir utilizando la TA.

En otros casos, cuando la distorsión es mayor, es posible que el usuario desista porque el esfuerzo que le supone enfrentarse al caos es demasiado grande. Aunque hoy en día las frases hechas sean más comunes, por una cuestión de simple estadística, suelen estar bien resueltas en la TA, una traducción literal del manido ejemplo It's raining cats and dogs («llueve perros y gatos»; «llueve a cántaros» sería lo inteligible) podría ofuscar al usuario y hacer que éste renuncie a conservar la información identificable (llueve), acuñando una evaluación escéptica sobre la TA. En algunos casos, la propuesta de TA es totalmente opaca como en "como el agua en la espalda del pato» para la frase hecha original en inglés water off duck's back, cuyo equivalente funcional sería la frase hecha en español peninsular «a palabras necias, oídos sordos». El grado de tolerancia del usuario ante el caos afecta, pues, al aprovechamiento de la TA.

Choi $^{25}$ llevó a cabo un interesante estudio con 20 sujetos (10 profesionales de la lengua y 10 usuarios de Internet no profesionales) y analizó la capacidad de ambos grupos para detectar errores de traducción. Lógicamente, el grupo de profesionales detectó más errores. Sin embargo, lo interesante de este estudio es que del grupo de no profesionales algunos usuarios no detectaron ningún error, lo cual parecía indicar un posible desistimiento inconsciente.

25 Yoonji Choi, «How Users Read Translated Web Pages: Occupational and Purpose-Based Differences», Tesis doctoral. Universitat Rovira i Virgili, 2016. 
Pero si el usuario necesita urgentemente la información, va a aceptar como valiosa la síntesis minimalista de la misma. Pongamos el ejemplo (real) de uno de nuestros estudiantes que sufre de alergias alimentarias y viaja a un país asiático sin conocer el idioma ${ }^{26}$. Muchos hombres y mujeres de negocios, así como turistas, pueden verse en esta situación y dudar, en el supermercado, de si pueden adquirir un producto u otro sin riesgo de padecer un episodio de alergia al consumirlo. En este caso se demostró que Google Lens (2017) traducía con faltas de precisión o fluidez la composición reseñada en los productos envasados, pero sí permitía obtener la información precisa sobre los posibles productos alergénicos, como se ve en la figura 1.

Figura 1. Ejemplo de TA de Google Lens 2017
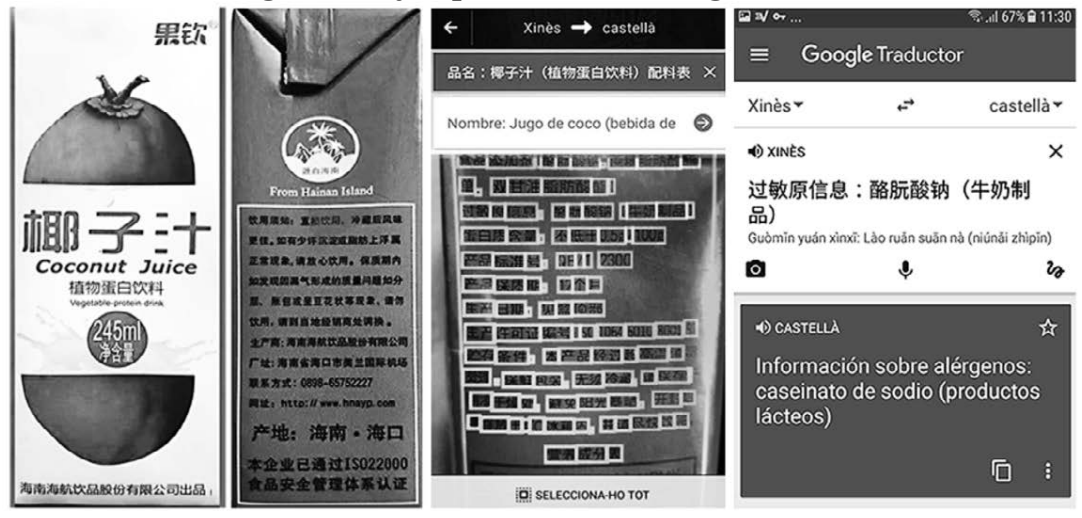

Fuente: Pérez-Carrascosa, 2018.

Otro campo en el que los usuarios realizan muchas consultas, aunque los médicos lo desaconsejen, es la medicina. De acuerdo con el volumen y la tipología de corpus en línea ${ }^{27}$, las áreas en las que más

26 Elena Pérez-Carrascosa, La traducción automática de productos alimentarios chino-español: el punto de vista del usuario con alergias alimentarias. Trabajo de fin de grado, dirigido por Anna Aguilar-Amat, Universidad Autónoma de Barcelona, 2018.

27 Miguel Ángel Candel-Mora y Chelo Vargas-Sierra, «An Analysis of Research Production in Corpus Linguistics Applied to Translation» Procedia. Social and Behavioral Sciences 95 (2013): $317-$ 324 (321). DOI: https://doi.org/10.1016/j.sbspro.2013.10.653. 
consultas de traducción automática son esperables son, por este orden: medicina, audiovisual, turismo, negocios y textos legales, seguidos por técnica, política, publicidad.

En el caso de la medicina, muchos usuarios realizan búsquedas y traducen la información médica en línea para orientarse sobre sus dolencias o las de sus familiares. En realidad, muchos de los textos publicados sobre este tema son ya de por sí traducciones automáticas. Un recurso muy utilizado como referente es Medline, la base de datos en línea más importante de la National Library of Medicine (NLM) que abarca campos de medicina, enfermería, odontología, veterinaria, salud pública y ciencias preclínicas. Desde sus orígenes en 1966, y con varias decenas de millones de referencias bibliográficas de artículos de revistas, Medline se sustenta en una institución prestigiosa, los National Institutes of Health (NIH). El $86 \%$ de la información es en inglés y gran parte de esta información es traducida a distintas lenguas por los usuarios que la consultan. A veces se indica el nombre del traductor humano, pero cierto tipo de errores son indicio del creciente uso de la $\mathrm{TA}^{28}$ : «El término inglés history on kidney disease es traducido por Google Translate como historia de la enfermedad del riñón». Medline utiliza la frase, historia de enfermedad renal. Pero el término historia tiene muchas acepciones y será la consulta de otros textos la que ayude a especificar que se trata de la historia clínica de la enfermedad renal».

Un estudio realizado por la NLM sobre cuál era el tipo de usuarios que accedían a Medline mostró que más del $40 \%$ de los que accedían a la base de datos era público general no especializado. A pesar de que la terminología médica, basada en étimos latinos y griegos, está muy consensuada y se muestra estable, existe una gran cantidad de variación denominativa, y la TA a veces contribuye a ello con más

28 María-Alexandra Milas, La traducción de términos oncológicos (cáncer de mama) en la base de datos MEDLINE. Trabajo de Fin de Grado dirigido por Anna Aguilar-Amat, Universidad Autónoma de Barcelona, 2014, p. 12. 
variación denominativa ${ }^{29}$, de manera que se podrían llegar a entender las propuestas de la TA dentro de la neologicidad:

Cuadro 3. Ejemplo de variación denominativa

\begin{tabular}{|l|l|}
\hline $\begin{array}{l}\text { anterior } \\
\text { cingulate cortex }\end{array}$ & $\begin{array}{l}\text { TA: *orteza cingulada anterior } \\
\text { Variaciones: } \\
\text { córtex del cíngulo anterior, cortex del cíngulo anterior, } \\
\text { circunvolución del cíngulo anterior, giro cingular anterior, } \\
\text { giro cingulado, gyrus cínguli }\end{array}$ \\
\hline
\end{tabular}

El usuario que traduce al español peninsular debe tener en cuenta que la TA ofrece las variaciones latinoamericanas por el hecho de ser estadísticamente superiores. En algunos casos eso no presenta un problema significativo, pero en función del encargo puede conllevar un malentendido grave. En el siguiente ejemplo del término drugs en inglés, en el lenguaje coloquial en español peninsular el término suele referirse a drogas ilegales y sustancias psicoactivas mientras que el término «fármaco» sería el propio para tratar enfermedades.

Cuadro 4. Variación denominativa dialectal o geográfica

\begin{tabular}{|l|l|l|}
\hline drugs & $\begin{array}{l}\text { *drogas, } \\
\text { fármacos }\end{array}$ & $\begin{array}{l}\text { En este texto se hace referencia al historial } \\
\text { farmacológico, pero no hay que descartar la } \\
\text { posibilidad de que en otros textos el término drug se } \\
\text { deba traducir por droga. }\end{array}$ \\
\hline
\end{tabular}

Otro aspecto estudiado en el marco de ProjecTA-U es la traducción automática de neologismos semánticos o, lo que es lo mismo, de colocaciones neológicas $^{30}$. Las colocaciones neológicas (traslaciones de significado) son una parte importante de la creatividad de los hablantes, pero impiden la 'cristalización' del proceso de traducción el cual «no puede estandarizarse como si se tratara de una actividad

29 José Arroyo Rosales, La traducción automática del léxico: TA de textos de medicina. Trabajo de fin de grado dirigido por Anna Aguilar-Amat, Universidad Autónoma de Barcelona, 2016.

30 Sofía Burgués Estrada y Anna Aguilar-Amat, «Las Colocaciones Neológicas y su Traducción Humana y Automática / Both Human and Machine Translation Challenges while Translating Neological Collocations», Revista REDILLET (Revista Digital Internacional de Lexicología, Lexicografia y Terminología) 2 (2019): 88-103. 
mecánica, ya que su mayor dificultad nace de la creatividad en el uso del idioma y de sus muy diversas y cambiantes finalidades a lo largo de la historia». En el cuadro 5 se observa la distorsión que causa la TA en estos casos.

Cuadro 5. Traducción de colocaciones neológicas

\begin{tabular}{|l|l|l|l|}
\hline $\begin{array}{c}\text { Colocación } \\
\text { neológica }\end{array}$ & \multicolumn{1}{|c|}{$\begin{array}{c}\text { Google } \\
\text { Translate } \\
\mathbf{( 2 0 1 8 )}\end{array}$} & \multicolumn{1}{|c|}{ Valoración } & \multicolumn{1}{|c|}{$\begin{array}{c}\text { Traducción correcta } \\
\text { documentada }\end{array}$} \\
\hline amigo invisible & invisible friend & $\begin{array}{l}\text { Incorrecto } \\
\text { Incomprensible }\end{array}$ & $\begin{array}{l}\text { Secret Santa / Kris } \\
\text { Kringle }\end{array}$ \\
\hline $\begin{array}{l}\text { camino de } \\
\text { rosas }\end{array}$ & path of roses & $\begin{array}{l}\text { Incorrecto } \\
\text { Comprensible }\end{array}$ & bed of roses \\
\hline $\begin{array}{l}\text { caja de los } \\
\text { truenos }\end{array}$ & thunderbox & $\begin{array}{l}\text { Incorrecto } \\
\text { Incomprensible }\end{array}$ & $\begin{array}{l}\text { Pandora's box / can of } \\
\text { worms }\end{array}$ \\
\hline vista oral & oral view & $\begin{array}{l}\text { Incorrecto } \\
\text { Incomprensible }\end{array}$ & oral hearing \\
\hline café para todos & $\begin{array}{l}\text { coffee for } \\
\text { everyone }\end{array}$ & $\begin{array}{l}\text { Incorrecto } \\
\text { Incomprensible }\end{array}$ & one-size-fits-all \\
\hline
\end{tabular}

Fuente: Elaboración propia.

Cuando el sistema incurre en un error con respecto al significado original y no logra una equivalencia correcta es debido a que el neologismo sintagmático (colocación) es reciente o bien desusado u obsoleto, ya que no alcanza la estadística necesaria en los corpus paralelos existentes para ser traducido correctamente por el programa.

Para los casos «Incorrecto/Comprensible» es posible que el usuario comprenda el significado de la colocación (i.e. thunderbox) y capte el mensaje, pero la naturalidad creativa del idioma y la distribución semántica se ven dañadas.

\section{Usuarios de la TA en proceso de adquisición del idioma}

En este grupo de usuarios hemos incluido a los estudiantes de secundaria de edades comprendidas entre los 11 y los 17 años, por un lado, y a los estudiantes de Traducción (20 a 25 años), por otro. En el 
primer subgrupo de los estudiantes de secundaria se han llevado a cabo dos tipos de aproximaciones desde nuestro grupo de investigación Tradumàtica: un estand sobre TA en una feria de iniciación a la ciencia para estudiantes de secundaria ${ }^{31}$ y una encuesta realizada por estudiantes para estudiantes en el marco de un programa de interrelación de la universidad con la enseñanza secundaria ${ }^{32}$ y en colaboración con ProjecTA-U (2019). En el primer caso, mediante varios ejemplos de errores humanos o de TA presentados a los estudiantes de la feria se constató que, por un lado, existía un tiempo de respuesta entre la percepción de un error textual y la correcta comprensión por parte de los jóvenes usuarios, y que esa transición temporal era mesurable. Por otro lado, a pesar de la motivación para entender una traducción con TAde la letra de una canción de Shakira (éxito del momento), un texto con gran diversidad de errores (morfosintácticos, léxicos, extralingüísticos, de orden, estilísticos), no era compresible para el usuario más que en un pequeño porcentaje, alrededor de un $10 \%$ de lo que sería su significado lírico.

Este primer encuentro motivó la necesidad de medir la relación del estudiante en formación que aún no posee seguridad sobre el uso del idioma y su conocimiento del mundo en su uso de la TA. Se trataba de averiguar si el estudiante, que utiliza la TA en diferentes momentos de su proceso formativo, es 1) consciente de los errores cometidos por la TA y 2) si es capaz de rectificarlos, o si, por el contrario, los asume de manera inconsciente como texto posible.

El resultado de las encuestas (realizadas en 2019 por estudiantes de bachillerato a otros estudiantes de su centro escolar de edades comprendidas entre los 11 y los 17 años en un total de 25 centros educativos españoles con una muestra total de 368 encuestados), presentaba como resultados que aproximadamente un $40 \%$ de los encuestados utilizaban

31 Olga Torres-Hostench, Anna Aguilar-Amat y Pilar Cid-Leal «Machine Translation Discussed with Young People» Science Communication 37(6), 2015: 795-804. <https://journals.sagepub.com/doi/ full/10.1177/1075547015610126>.

32 Argó, Programa del Instituto de Ciencias de la Educación de la UAB de apoyo a la transición entre la secundaria y la universidad, marzo 2020, <https://www.uab.cat/web/programa-argo-1345714880943.html>. 
la TA en sus actividades escolares o extraescolares. De estos, utilizaban la TA como un diccionario (49\%) y un $47 \%$ utilizaban documentación traducida de otras lenguas para sus trabajos académicos. En un $84 \%$ de estos últimos, el inglés era mayormente la lengua original de la documentación traducida. De la misma muestra se desprende que los estudiantes encuestados fueron capaces de identificar errores de traducción automática a su lengua materna en un $67 \%$ del total, mientras que el $33 \%$ de estudiantes no percibieron los errores de la TA.

Para diseñar esta encuesta se tuvo en cuenta la bibliografía existente sobre evaluación de calidad de TA en general. En los tests o pruebas tradicionales a usuarios se presenta una frase y los usuarios deben puntuar en una escala del 1 al 5 en función del grado de fidelidad o inteligibilidad ${ }^{33}$. Cabe señalar que los resultados del sondeo son solo aproximativos y que se proporcionan aquí por la importancia que tiene este grupo de usuarios como usuarios futuros.

En el caso de los estudiantes universitarios de Traducción en formación (proceso de adquisición de una segunda lengua) se ha realizado un estudio sobre cómo la TA es utilizada por los estudiantes chinos en el aprendizaje de español. Partiendo de la premisa de que la TA es útil, especialmente para la adquisición de vocabulario, Clifford et $\mathrm{al}^{34} \mathrm{y}$ Zhang y Torres-Hostench ${ }^{35}$, elaboran una propuesta didáctica para la posedición de errores de traducción automática (TA) mediante pretest/postest con grupo de control y grupo experimental. En este caso concreto, los resultados mostraron que los estudiantes detectaron más rápidamente los errores de tipo registro formal, omisión y preposición. Sin embargo, los errores de precisión léxica, al ser más ambiguos, fueron más difíciles de detectar. Este trabajo está enmarcado en la tesitura de usar la posedición

33 Chan Sin-Wai, Routledge Encyclopedia of Translation Technology (Londres: Routledge, 2014).

34 Joan Clifford, Lisa Merschel y Joan Munné, «Tanteando el terreno: ¿Cuál es el papel de la traducción automática en el aprendizaje de idiomas?»@tic. revista d'innovació educativa 10 (2013): 108-121. DOI: $10.7203 /$ attic.10.2228.

35 Hong Zhang y Olga Torres-Hostench «Cómo enseñar posedición de traducción automática a una segunda lengua: una propuesta didáctica para el aprendizaje de lenguas» Revista Tradumática 17 (2019). <https://doi.org/10.5565/rev/tradumatica.237>. 
con fines docentes e incrementar la habilidad del traductor en su relación con el caos como poseditor. Esta capacidad de detectar errores se puede fomentar e incorporar en la formación de los futuros traductores.

En la línea de Torrejón y Rico ${ }^{36}$, las habilidades del futuro poseditor se podrían agrupar en tres categorías principales: competencias nucleares, habilidades lingüísticas y competencias instrumentales. Las competencias nucleares están directamente relacionadas con las competencias actitudinales y psicofisiológicas que permiten resolver problemas de subjetividad respecto a la calidad textual y a la resolución de dudas. Las habilidades lingüísticas se refieren a la competencia en la lengua materna (conocimientos extralingüísticos, temáticos y de producción textual). Las competencias instrumentales implican entender cómo funciona la traducción automática incluyendo su funcionamiento (ya sean sistemas basados en reglas, en corpus, de traducción estadística, neural o híbridos) y su potencial, gestión de memorias de traducción y terminología, control de calidad de corpus textuales, etc.

\section{Aspectos cognitivos del usuario de la TA}

Todos los usuarios de la TA son hablantes de una lengua y comparten un proceso básico de inteligibilidad como receptores de un texto. Se les supone pues un nivel de competencia y actuación lingüística ${ }^{37}$. La actuación o performance describe la conducta lingüística real y observable en contraste con el sistema interno de conocimiento que subyace a ella (competencia), es decir, la facultad la abstracción de los juicios de un hablante/ oyente ideal de una comunidad lingüística homogénea, al que no afectan limitaciones de memoria, distracciones, errores, etc. A esta competencia atribuimos la capacidad del hablante de compensar las ausencias y llenar los huecos de la TA.

36 Enrique Torrejón y Celia Rico, «Habilidades y perfil del nuevo rol del traductor como poseditor de traducción automática» Revista Tradumática 10 (2012): 166-178.

37 Noam Chomsky, Aspects of the Theory of Syntax (Cambridge, Mass.: The M.I.T. Press, 1965) 3. 
En psicología se llama compensación a la «superación o reducción de las pérdidas o déficits en diferentes mecanismos y procesos cerebrales $\rangle^{38}$. Así pues, la compensación es un fenómeno psicológico más allá de la comunicación verbal, y se pueden considerar «dos principales atributos a la hora de definir una herramienta compensatoria: (i) ayudan al individuo a realizar algunas de sus actividades cotidianas; (ii) pueden adaptarse a las necesidades particulares de un individuo ${ }^{39}$.

Los ejemplos del cuadro 6 pueden dar una idea de cómo funciona nuestra mente en los procesos de compensación.

\section{Cuadro 6. Ejemplos}

(1) A pesar de que resulta sorprendente, nuestro cerebro es capaz de descifrar códigos y de leer y comprender párrafos en los que las letras están cambiadas de lugar:

Sgeun un etsduio de una uivenrsdiad ignlsea, no ipmotra el odren en el que las ltears etsan ersciats, la uicna csoa ipormtnate es que la pmrirea y la utlima ltera esetn ecsritas en la psiocion cocrrtea

Fuente: http://blog.zana.es/sobre-como-lee-nuestro-cerebro/

(2) Han sido sustituidas por números que se asemejan a las letras en su forma: C13R70 D14 D3 V3R4N0 3574B4 3N L4 PL4Y4 0853RV4ND0 4 D05 CH1C45 8R1NC4ND0 3N 14 4R3N4. 357484N 7R484J484NDO MUCH0 C0N57RUY3ND0 UN C4571LL0 D3 4R3N4 C0N 70RR35, P454D1Z05, 0CUL705 Y PU3N735. CU4ND0 357484N 4C484ND0 V1N0 UN4 0L4 D357RUY3ND0 70D0 R3DUC13ND0 3L C4571LL0 4 UN M0N70N D3 4R3N4 Y 35PUM4. P3N53 9U3 D35PU35 DE 74N70 35FU3RZ0 L45 CH1C45 C0M3NZ4R14N 4 L10R4R, P3R0 3N V3Z D3 350, C0RR13R0N P0R L4 P14Y4 R13ND0 Y JU64ND0 Y C0M3NZ4R0N 4 C0N57RU1R 07R0 C4571LL0. C0MPR3ND1 9U3 H4814 4PR3ND1D0 UN4 6R4N L3CC10N

Fuente: http:/hup.com.es/docs/formacion/2016/01-neuromarketing.pdf

38 Lars Bäckman y Roger A. Dixon, «Psychological Compensation: A Theoretical Framework», Psychological Bulletin 112, 2 (1992): 259-283.

39 Mauricio Iza Mikeleiz y Alexandra Konstenius, «Tecnología para compensación de memoria» Avances en neurología Av Neurol. 2, 2 (2011) : 1, <http://hdl.handle.net/10401/3535>. 
Aunque las capacidades sintácticas y semánticas de los individuos se utilizan para su evaluación neuropsicológica y el psicólogo clínico tiene en cuenta la interfaz de funciones lingüísticas con otras funciones cognitivas como las funciones perceptivas, ejecutivas y de memoria episódica, no es el propósito de esta investigación revertir el proceso para evaluar las posibilidades de reparación de los individuos ante textos alterados léxica y morfosintácticamente por la traducción automática, sino describir y asumir una cierta habilidad dinámica de compensación del texto.

El concepto de compensación originado en el campo de la psicología pasó a la Traducción como uno de los procedimientos técnicos posibles. En 1958 Vinay y Darbelnet ${ }^{40}$ realizaron la primera clasificación de procedimientos técnicos puntuales usados para traducir un texto. Estos son: la adaptación (reemplazar un elemento cultural del texto original por otro propio de la cultura receptora), la ampliación lingüística (añadir elementos lingüísticos por razones estructurales o cuando es necesario solucionar una ambigüedad), y la compensación (mezcla de reducción - eliminación de elementos redundantes-y de expansión —adición de elementos - para expresar matices y recuperar el efecto correspondiente al original).

En el caso que nos ocupa de la TA, sin embargo, la compensación que hace el usuario no es solo expandir o suprimir, sino que se enfrenta a errores cometidos por la máquina que distorsionan en mayor o menor medida la semántica del texto. Ante estos déficits puede haber distintos tipos de respuestas posibles tales como una reparación fáctica, una reparación lingüística, etc., como se presenta en el siguiente ejemplo del cuadro 6, en una receta para hornear scones (bollos escoceses), se han marcado los puntos calientes que precisan de compensación.

40 Jean Paul Vinay y Jean Darbelnet, Stylistique comparée du français et de l'anglais: méthode de traduction (París: Marcel Didier: 1958). 
Cuadro 6. Traducción de una receta para hacer scones.

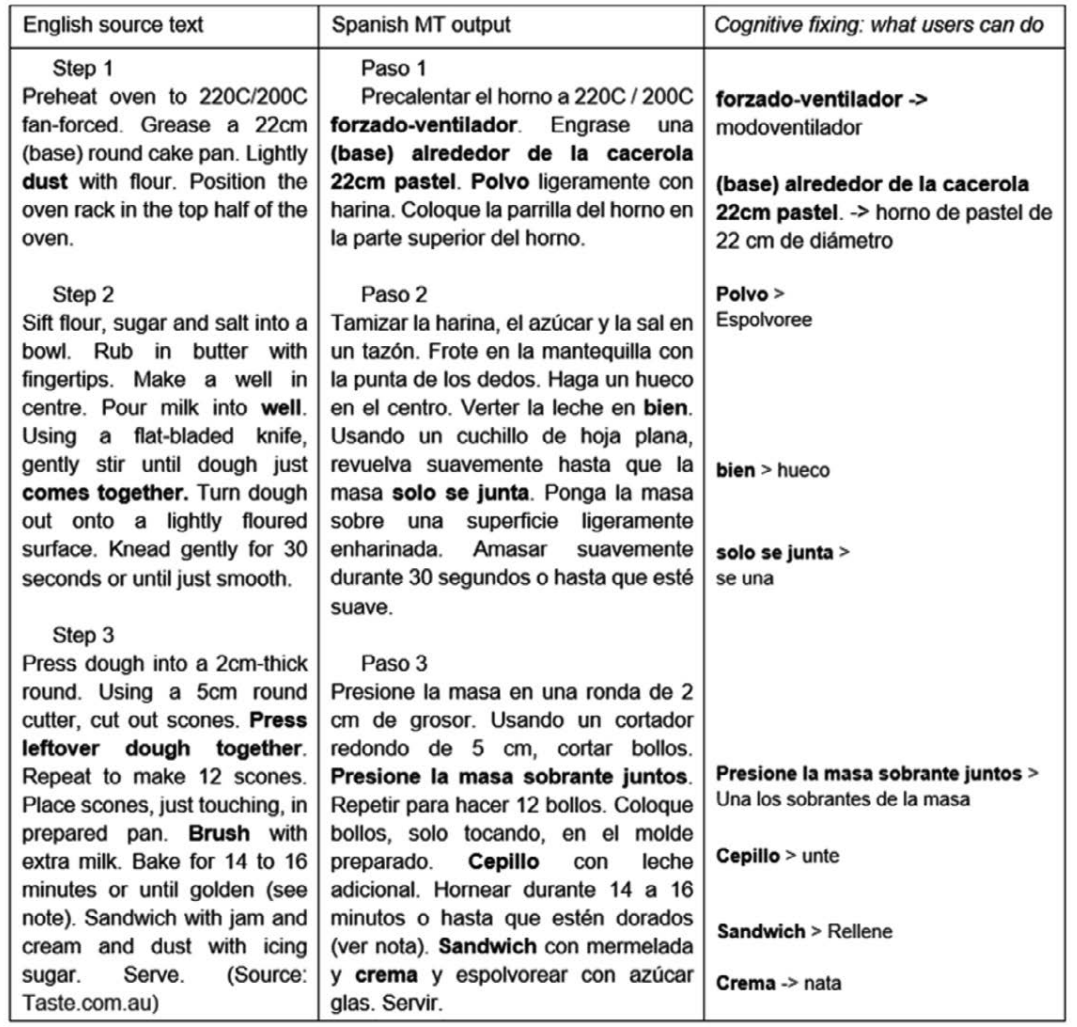

Fuente: Elaboración propia.

Del ejemplo anterior destacamos tres aspectos claves que afectan la comprensión del usuario: 1. El término inglés well aparece en el texto dos veces, traducido la primera vez correctamente (hueco) y la segunda vez incorrectamente como el adverbio 'bien'. En este caso el usuario debe poseer una capacidad anafórica que le permita comprender fácticamente que, si ha hecho un hueco y luego hay que verter la leche, lo vertido va a ser en ese hueco, aunque en el texto no solo no está expresado correctamente, sino que existen elementos distorsionadores (reparación fáctica). 2. El verbo denominal sandwich 
en inglés no se traduce correctamente como 'rellenar'. El usuario debe realizar la inferencia metafórica (reparación lingüística). 3. El inglés cream (en el campo de la gastronomía) es un falso amigo. Debería traducirse por 'nata' y no como 'crema' ya que en español la crema (crema pastelera) se hace hirviendo leche, azúcar y huevo.

Existe un amplio abanico de intentos dirigidos a medir la capacidad comunicativa de la TA. En las pruebas de inteligibilidad se utiliza el calificativo de comprensible para medir la capacidad del usuario de aprehensión del contenido principal del mensaje. De entre los distintos procedimientos uno consiste en entregar a los sujetos frases traducidas con traducción automática y formular preguntas de comprensión ${ }^{41}$. Otro procedimiento es el denominado cloze procedure, probado por Somers y Wild ${ }^{42}$, Forcada y $\operatorname{otros}^{43}$ y Jones et. $\mathrm{al}^{44}$, que consiste en presentar unas frases de traducción automática con huecos para que los sujetos adivinen la palabra que debe ir en el hueco. Si los sujetos entendían las frases que rodeaban la palabra omitida eran capaces de adivinar la palabra en cuestión. Es decir, entendían la traducción automática. Otros estudios han intentado determinar los factores que intervienen en la comprensión de la TA. Por ejemplo, Aiken y otros ${ }^{45}$ realizaron estudiaron la importancia de la fluidez idiomática en la

41 Masaru Tomita, Masako Shirai, Junya Tsutsumi, Miki Matsumura y Yuki Yoshikawa, «Evaluation of MT Systems by TOEFL» Proceedings of the Theoretical and Methodological Implications of machine translation (TMI-93) (1993); y J. White, J., O'Connell, T. y O'Mara, F. (1994, October). «The ARPA MT evaluation methodologies: evolution, lessons, and future approaches», Proceedings of the 1994 Conference, Association for Machine Translation in the Americas, 193-205.

42 Harold Somers y Elisabeth Wild, «Evaluating Machine Translation: The Cloze Procedure Revisited» Translating and the Computer,22 Proceedings of the Twenty-second International Conference on Translating and the Computer (2000) <https://pdfs.semanticscholar.org/061f/fbfc489b284ec60cca205a8aebc30243e3f3.pdfs.

43 Mikel Forcada, Carolina Scarton, Lucia Specia, Barry Haddow, Alexandra Birch, «Exploring Gap Filling as a Cheaper Alternative to Reading Comprehension Questionnaires when Evaluating Machine Translation for Gisting», Proceedings of the 3rd Conference on Machine Translation (WMT18), 2018: 192-203, <arXiv:1809.00315v1>.

44 Douglas Jones, Wade Shen, Martha Herzog, «Machine Translation for Government Applications» Lincoln Laboratory Journal 18, 1 (2009).

45 Miliam Aiken, Mina Park y Tobin Lindblom «Language Fluency as a Factor in Machine Translation Comprehension», International Journal of Computers and Technology, 10(2), (2013): $1349-1355$. 
comprensión de la TA. A su vez, Vanjani, Aiken y Park ${ }^{46}$ preguntaron a 96 estudiantes universitarios lo que significaban varios párrafos traducidos con TA. Sus hipótesis relacionaban la comprensión lectora de la TA con el interés y la motivación (Hipótesis H1), con la fluidez en el idioma meta $(\mathrm{H} 2)$, con la fluidez en el idioma extranjero $(\mathrm{H} 3)$ y con los conocimientos sobre el tema del texto (H4). Cabe señalar que los resultados del estudio no validaron ninguna de las hipótesis.

Como se desprende de la receta de scone traducida, en la medida que, por conocimiento o motivación en la recepción del mensaje, el receptor comprende las limitaciones de la TA, puede crear un flujo de simpatía que le permite reparar cognitivamente la forma del mensaje para compensar las deficiencias de la TA.

En la figura 2 se observa en qué lugar del modelo funcional de la comunicación de Roman Jakobson se situaría la función empática. En su teoría de la información, constituida en $1958^{47}$ y articulada en torno a los factores de la comunicación (emisor, receptor, referente, canal, mensaje y código), Jakobson dedujo la existencia de seis funciones del lenguaje: la expresiva, la apelativa, la representativa, la fática, la poética y la metalingüística. Desde entonces se han propuesto modificaciones a su esquema operativo para que otras funciones como la lúdica o la estética también tuvieran cabida. Sin entrar en la polémica vemos cómo la función empática podría ser una propuesta enriquecedora. La figura 2 representa de una manera simplificada el proceso según el cual el receptor de TA es capaz de generar un mensaje comprensible a partir de un resultado de la TA con errores, es lo que hemos llamado empatía cognitivo-comunicativa.

46 Mahesh Vanjani, Milan Aiken y Mina Park, «A Study of Factors Influencing Machine Translation Comprehension» QRBD, (2015): 121-132.

47 Roman Jakobson, Closing Statements: Linguistics and Poetics, Cambridge, MA: MIT Press, 1960. 
Figura 2. La función empática a partir del modelo de Roman Jakobson

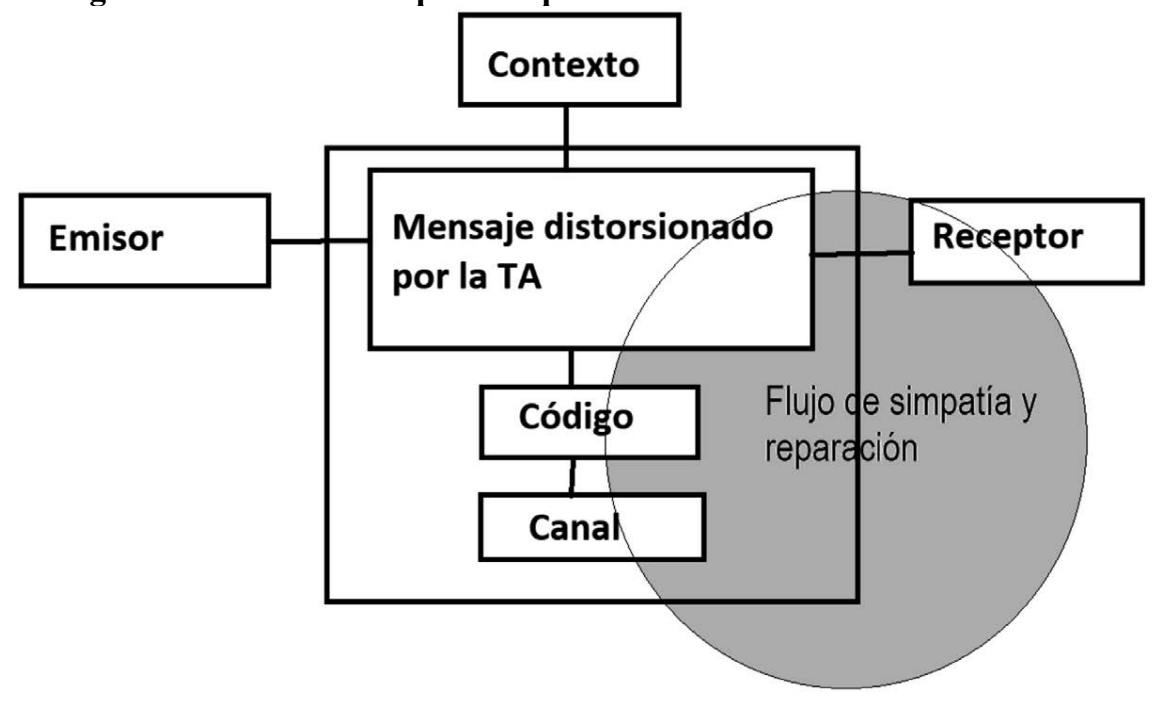

Fuente: elaboración propia.

La teoría de la comunicación de Jakobson (1958) planteó seis tipos de funciones en torno a los factores de la comunicación (emisor: función expresiva; receptor: función apelativa; contexto: función referencial; mensaje: función poética; código: función metalingüística; y canal: función fática). La reparación cognitiva que seguiría a la empatía afecta a las funciones conativas (receptor), poética (mensaje) y metalingüística (código). Al receptor, porque se convierte en actante (segundo emisor de un mensaje reparado emitido por él mismo hacia sí mismo) y responsable consciente de lo que percibe/recibe/escucha/ lee; al mensaje, porque sufre una doble distorsión, la que ha producido la traducción automática y la que el receptor efectúa para compensar las distorsiones o errores, y el código se ve afectado por la contrastividad entre los dos sistemas lingüísticos y sus universos conceptuales.

Si se puede medir/incidir en la empatía cognitiva para predecir/ mejorar la efectividad de la comunicación multilingüe, las funciones conativa, poética y metalingüística serán las afectadas por una evolución 
de las competencias tal y como se ve en el cuadro 7. Desarrollo de la empatía cognitiva de los usuarios de la TA. El concepto de empatía cognitivo-comunicativa selectiva es próximo al de bounded rationality 'racionalidad limitada' de Herbert A. Simon ${ }^{48}$. De acuerdo con Simon, las personas simplemente intentan buscar una mínima satisfacción, es decir, tratan de alcanzar ciertos niveles de éxito para después, poco a poco, ir ajustando esa solución. Esta estructura de pensamiento que Simon denominó racionalidad limitada estimuló muchos trabajos posteriores sobre el comportamiento de los individuos, las organizaciones y la sociedad. Simon apunta que la racionalidad personal está de hecho limitada por tres dimensiones: 1) la información disponible, 2) la limitación cognoscitiva de la mente individual y 3) el tiempo disponible para tomar la decisión. Estas tres dimensiones afectan directamente a la empatía cognitivo-comunicativa efectuada por el usuario sobre el resultado de la traducción automática.

Este principio de mínima satisfacción planteado por Simon es el más próximo al concepto propuesto en este artículo, que hemos denominado empatía cognitivo-comunicativa: el usuario se esfuerza en «reparar» la traducción hecha por la TA, pero a veces solo hasta el punto de estar satisfecho — sin ir más allá-, es decir, la empatía predispone al usuario a la compensación, y la satisfacción supone el límite de la compensación. La empatía cognitivo-comunicativa tendría otro eco del pasado en el marco de lo que se ha denominado gist translation o traducción provisional para la asimilación de información. Se suele denominar gist translation a la traducción automática que no ha sido poseditada ${ }^{49}$. Se trata de una traducción básica, sin pulir, que sirve para ver las ideas esenciales de un texto y saber de qué trata sin que en ningún caso sea una traducción precisa. Esta modalidad de traducción se empezó a utilizar en entornos militares o de inteligencia, por ejemplo, en los que se leían grandes cantidades de información y

48 Herbert A. Simon, The Sciences of the Artificial. Massachusetts: The MIT Press, 1996.

49 Lucía V. Aranda, Handbook of Spanish-English Translation (Lanham: University Press of America, 2007). 
lo importante era la rapidez antes que el contenido detallado. La gist translation podía ser realizada por traductores humanos -en general aficionados- (que resumían muy por encima un texto), o por traductores automáticos. En la sociedad digital actual en la que el acceso a toda la información tiene que ser inmediato, es una modalidad cada vez más habitual, y en muchos casos la única posibilidad de acceso a la información.

Medir la capacidad de comprensión del receptor que lee un texto proveniente de la traducción automática con los inevitables errores lingüísticos y extralingüísticos que pueda contener es útil para los estudios de mercado (consumidores), pacientes (medicina), estudiantes... así como también permite evaluar a profesionales contratados en las empresas de traducción, destinarles textos de su especialidad y obtener mayor rigor en el resultado con menos tiempo invertido. Los beneficios son tanto lucrativos como humanos. Así lo intuyeron anteriormente en el proyecto europeo $\mathrm{ACCEPT}^{50}$ en el que se estudió de qué manera los usuarios de foros de Internet podrían mejorar su comunicación multilingüe mediante el uso de traducción automática. Por su parte, Anazawa y otros ${ }^{51}$ llevaron a cabo un estudio sobre el uso de la traducción automática entre enfermeras japonesas que querían acceder a publicaciones sobre enfermería en inglés. El objetivo consistía en analizar cómo era el uso de la TA, el grado de usabilidad y cómo podría mejorar la utilización de la TA para romper la barrera lingüística. De las 250 enfermeras, un 73,8 \% habían utilizado TA para acceder a ese tipo de publicaciones y más de la mitad afirmaron que el contenido era aprovechable. Doherty y O'Brien ${ }^{52}$ investigaron la usabilidad de un mismo sistema de traducción automática con

50 ACCEPT (2015). ACCEPT project: Automated Community Content Editing PorTal. Grant agreement No. 288769, marzo 2020, <https://www.accept.unige.ch/>.

51 Ryoko Anazawa, Hirono Ishikawa, Mj Park y Takahiro Kiuchi, «Online machine translation use with nursing literature: evaluation method and usability», CIN: Computers, Informatics, Nursing 31, 2 (2013): 59-65.

52 Stephen Doherty and Sharon O'Brien, «Assessing the usability of raw machine translated output: A user-centered study using eye tracking», International Journal of Human-Computer Interaction, 30,1 (2014): 40-51.<https://doi.org/10.1080/10447318.2013.802199> 
cuatro combinaciones lingüísticas distintas. Con usuarios nativos de las lenguas de llegada midieron la usabilidad, la satisfacción, la efectividad y eficiencia de la traducción automática de cada combinación y constataron que la usabilidad dependía en gran medida de la combinación lingüística.

Frente a los déficits de usabilidad de la TA, el usuario desarrolla ciertas aptitudes adaptativas, relacionadas también con otras circunstancias actuales de la comunicación en la era digital, por ejemplo, el fenómeno creciente de internacionalización y multilingüismo que se ha descrito como 'competencia comunicativa intercultural' ${ }^{53}$ en la que se describen tres dimensiones básicas en la comunicación humana: (i) la actitud (incluye el entendimiento, la adaptación, la flexibilidad, la empatía); (ii) el conocimiento (incluye la conciencia, el estilo de vida, la cultura, los estereotipos); (iii) el comportamiento (incluye el respeto, la educación, el decoro).

En cuanto a la detección de errores de la TA y la posibilidad de reparación por el usuario, los diferentes aspectos a valorar expuestos en los estudios anteriores pueden verse en el cuadro 7.

53 Michael Byram y Carol Morgan, «Teaching-and-learning language-and-culture», Multilingual Matters, 100 (1994); y Fritz Wolfgangz, Antje Möllenberg y Guo-Ming Chen, «Measuring Intercultural Sensitivity in Different Cultural Contexts», Intercultural Communication Studies 11,2 (2002). <https://web.uri.edu/iaics/files/12-Wolfgang-Fritz-Antje-Mollenberg.pdf> . 
Cuadro 7. Desarrollo de la empatía cognitiva

\begin{tabular}{|c|c|c|}
\hline \multicolumn{3}{|c|}{ Desarrollo de la empatía cognitiva de los usuarios de la TA } \\
\hline $\begin{array}{l}\text { Receptor: función } \\
\text { conativa }\end{array}$ & Mensaje: función poética & $\begin{array}{l}\text { Código: función } \\
\text { metalingüística }\end{array}$ \\
\hline \multirow[t]{4}{*}{ Respuesta activa } & $\begin{array}{l}\text { Información lingüística } \\
\text { (competencia del idioma) }\end{array}$ & \multirow{2}{*}{$\begin{array}{l}\text { Morfosintaxis y semántica de } \\
\text { la lengua de llegada en modo } \\
\text { velado, conocimiento del } \\
\text { mundo en modo activo }\end{array}$} \\
\hline & $\begin{array}{l}\text { Información } \\
\text { extralingüística } \\
\text { (documentación) } \\
\end{array}$ & \\
\hline & Detección de errores & \multirow{2}{*}{$\begin{array}{l}\text { Toma de decisiones léxicas, } \\
\text { orden de la oración, } \\
\text { topicalización del mensaje }\end{array}$} \\
\hline & \begin{tabular}{|l|} 
Delimitación de la \\
contrastividad conceptual
\end{tabular} & \\
\hline \multirow[t]{3}{*}{$\begin{array}{l}\text { Respuesta } \\
\text { proactiva }\end{array}$} & \begin{tabular}{|l} 
Superación de la \\
ansiedad ante el caos
\end{tabular} & \begin{tabular}{|l|}
$\begin{array}{l}\text { Confianza empática } \\
\text { cognitivo-comunicativa }\end{array}$ \\
\end{tabular} \\
\hline & Motivación / Satisfacción & \begin{tabular}{|l|} 
Racionalidad vinculada al \\
objetivo de la comunicación
\end{tabular} \\
\hline & Conciencia intercultural & $\begin{array}{l}\text { Intercultural Communication } \\
\text { Competence (ICC) }\end{array}$ \\
\hline
\end{tabular}

Esta aproximación descriptiva sitúa el proceso empático cognitivo-comunicativo del usuario general en la recepción de TA, permite adecuar el mensaje a cada tipo de receptor y predecir para cada tipo de mensaje cuál será la recepción final por el usuario medio. El éxito de la TA depende en gran parte del receptor, y puede que esto sea así para todo acto comunicativo. Puesto que el lenguaje es un organismo vivo y cambiante y la TA siempre va a cometer errores, la empatía del usuario es fundamental en el proceso de comunicación y por eso lo hemos convertido en objeto de atención en este artículo.

\section{«Last but not least»}

Como afirman Krings y Koby (2001:5), «machine translation has long been studied and analyzed to better understand and enhance the process. What has been neglected, however, is the study of post-editing and the mental processes involved». Desde 2001 ha habido un gran 
avance en la valoración de los procesos de posedición porque era de interés para la traducción profesional ${ }^{54}$. En cambio, por la enormidad de la muestra y la diversidad de tipos, ha habido pocas aproximaciones empíricas a los usuarios no profesionales de la TA, cuando su protagonismo es cada vez mayor, y cuando su respuesta cognitiva no solo es importante en términos de mercado y de comunicación global, sino que aporta información sobre los procesos cognitivos de la Traducción y la Comunicación intercultural en sí misma. En este artículo se pretende dar algunos pasos en esta línea de investigación, aunque somos conscientes de que un trabajo sistemático requeriría una mayor tipificación de los usuarios y de sus objetivos.

A pesar de las distorsiones morfosintácticas, semánticas y terminológicas que pueden afectar la forma y el contenido de un texto resultado de un proceso de traducción automática, a pesar de que la distancia entre idiomas (mayor o menor presencia de corpus de textos paralelos en línea) es un factor clave en la inteligibilidad del resultado final, la traducción automática es una herramienta útil y una parte importante del mensaje llega al receptor porque éste es capaz de «repararlo cognitivamente» (reestructurar, reemplazar, aportar partes del contenido y de la forma). La utilidad de la TA y la satisfacción final obtenida están directamente relacionadas con la motivación inicial, con la evaluación inicial y con la capacidad de empatía cognitivo-comunicativa.

Además de los criterios de preedición y posedición, es posible entrenar a los usuarios de TA en estrategias de empatía cognitivocomunicativa y competencia intercultural. En esta formación se mostrarían diferentes tipos de errores y cómo repararlos. La formación implica ir más allá del efecto a veces hilarante de los errores de la traducción automática de frases sin contexto. En los procesos de

54 Sharon O’Brien, Laura Winther Balling, Michael Carl, Michael Simard y Lucia Specia (eds.), Post-editing of machine translation: Processes and applications (Cambridge: Cambridge Scholars, 2014). 
automación de la Traducción ${ }^{55}$ se produce un proceso simbiótico del trabajo computacional del ordenador (estadístico y algorítmico), y la capacidad recreativa (empatía cognitivo-comunicativa) del traductor o del usuario.

«Humanizar» las máquinas, es también un factor a favor de la nueva era. Poner un nombre humano al sistema o presentar al sistema de TA como un asistente animado. Microsoft, por ejemplo, en la nota de exención de responsabilidad que incluía al final de todas las traducciones automáticas de su Knowledge Base, se indicaba que «los artículos traducidos automáticamente pueden contener errores en el vocabulario, la sintaxis o la gramática, como los que un extranjero podría cometer al hablar otro idioma». Sin duda, es una manera de humanizar el sistema para conseguir la empatía de los usuarios.

Siendo la TA una herramienta con una expectativa de uso creciente, y dada la implicación del usuario, la reflexión sobre la experiencia del usuario final con la TA puede conseguir un acercamiento de expectativas, una reivindicación de lo conseguido por la TA hasta el momento y un planteamiento de aprovechamiento eficaz de la calidad actual:

In the end, the group agreed: A new approach to quality assessment is needed. We must move away from an internal focus on measuring translation metrics. Instead, we ought to look outside and review translation quality in the context of end customer success and user experience ${ }^{56}$.

En la misma línea de este artículo, y basándose en los factores a medir según $\mathrm{ISO}^{57}$ : eficiencia, efectividad y satisfacción, Castillo y

55 Anna Aguilar-Amat, «Traducción, computación, utopía. Terminologie et Traduction», Punto y coma. Boletín de los traductores españoles de las instituciones de la Unión Europea 73, (2002): 15-50.

56 Andrew Lawless, How the power of the end-user kills quality control (2014), <https://www.taus. net/think-tank/articles/event-articles/how-the-power-of-the-end-user-kills-quality-control>.

57 International Organization for Standardization. ISO/TR 16982: Ergonomics of human-system interaction - Usability methods supporting human centered design.2020, fecha de consulta: diciembre de 2019, <http://www.iso.org/iso/catalogue_detail?csnumber $=31176>$. 
otros $^{58}$ presentaban resultados sobre indicadores cognitivos basados en el rastreo de la mirada (eye tracking), pero queda todavía un largo camino para medir el progreso humano en su interacción con la máquina.

Los usuarios van a experimentar un efecto clave en la mejora de la TA y en la información que se va a globalizar, ya sea en la creación de nueva terminología, nuevos géneros, nuevos formatos, etc. Las herramientas de traducción automática ya están incluyendo el feedback de los usuarios junto a las propuestas, con el fin de mejorarlas. A su vez, la percepción del usuario también irá mejorando a medida que se acostumbre a la traducción automática, y aumente su empatía cognitivo-comunicativa. Con la práctica, podrá diferenciar mejor y más rápido lo que son defectos de forma y lo que son defectos de contenido. Evaluar la capacidad de empatía cognitivo-comunicativa del usuario permitirá evaluar también la capacidad de comprensión de los contenidos digitales.

A modo de resumen, se destacan las siguientes conclusiones:

- Un estudio empírico de la TA debe diferenciar distintos tipos de usuarios.

- $\quad$ El éxito de la TA depende en gran parte del proceso de recepción del usuario.

- $\quad$ Es posible adecuar el mensaje a cada tipo de receptor y predecir para cada tipo de mensaje cuál será la recepción final por el usuario medio.

- $\quad$ Puesto que el lenguaje es un organismo vivo y cambiante y la TA siempre va a cometer errores, la empatía del usuario es fundamental en el proceso de comunicación y por eso lo hemos convertido en objeto de atención en el artículo.

58 Sheila Castilho, Sharon O’Brien, Fabio Alves, y Morgan O’Brien, «Does Post-editing Increase Usability? A Study with Brazilian Portuguese as Target Language», Proceedings of the Seventeenth Annual Conference of the European Association for Machine Translation, junio de 2014: 16-18. <http://doras.dcu.ie/19997/1/PE_Usability_EAMT2014_Camera_ready.pdf $>$. 
- Los errores de la TA pueden aumentar la conciencia lingüística del usuario.

- La función empática es un complemento al modelo funcional de Jakobson.

Asimismo, concluyamos con esta cita de la revista Wired en $2012^{59}$ :

The answer lies in humans as intelligent end users. (...) Likewise, people who take raw machine translations and edit for idioms, colloquialisms and other cultural nuances will overcome the hurdle that separates bulk translation from good translation.

La empatía cognitivo-comunicativa no es ni más ni menos que la asunción del usuario como ser inteligente, y al mismo tiempo la conciencia de que el camino para obtener un resultado de calidad suele conllevar esfuerzos suplementarios. La predisposición empática supone una gran parte del éxito en cualquier contexto de comunicación. Bien pudiere ser que en la interacción con una máquina, desarrollar empatía para entender sus limitaciones nos permitiría aumentar nuestras habilidades en la comunicación entre humanos.

59 Wired. «Users Bring Real Value to Big Data, Machine translation. Human, Meet Machine» (20129, $<$ http://www.wired.com/insights/2012/09/end-users-big-data/ $>$. 
